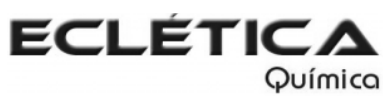

www.scielo.br/eq

www.ecletica.iq.unesp.br

Volume 33, número 2, 2008

\title{
Simple and sensitive spectrophotometric methods for the determination of acebutolol hydrochloride in bulk sample and pharmaceutical preparations
}

\author{
D.H. Manjunatha, S.M.T. Shaikh, K. Harikrishna, R. Sudhirkumar, \\ P.B. Kandagal and J. Seetharamappa* \\ Department of Chemistry, Karnatak University, Dharwad- 580 003, India \\ *j_seetharam@rediffmail.com
}

\begin{abstract}
A direct, extraction-free spectrophotometric method has been developed for the determination of acebutolol hydrochloride $(\mathrm{ABH})$ in pharmaceutical preparations. The method is based on ionpair complex formation between the drug and two acidic dyes (sulphonaphthalein) namely bromocresol green (BCG) and bromothymol blue (BTB). Conformity to Beer's law enabled the assay of the drug in the range of 0.5-13.8 $\mu \mathrm{g} \mathrm{mL}^{-1}$ with $\mathrm{BCG}$ and 1.8-15.9 $\mu \mathrm{g} \mathrm{mL}^{-1}$ with BTB. Compared with a reference method, the results obtained were of equal accuracy and precision. In addition, these methods were also found to be specific for the analysis of acebutolol hydrochloride in the presence of excipients, which are co-formulated in the drug.
\end{abstract}

Keywords: acebutolol hydrochloride; spectrophotometry; pharmaceutical preparations.

\section{Introduction}

Chemically, acebutolol hydrochloride (Fig 1) is (N-[3-Acetyl-4-[2-hydroxy-3[(1-methylethyl)amino]propoxy]phenyl]butanamide) hydrochloride, is a cardio-selective betablocker used in the management of hypertension, angina pectoris and cardiac arrhythmias[1], which normalizes the blood pressure and prevents the occurrence of hypertensive crisis. The Official method[2] for the determination of $\mathrm{ABH}$ is non-aqueous titration technique detecting the end point potentiometrically in aqueous medium using $0.1 \mathrm{M} \mathrm{NaOH}$ titrant. Several methods are reported in the literature for the determination of the beta-blockers including spectrophotometry [3-7], NMR[8,9], high performance liquid chromatography[10-13], thin layer chromatography[14], liquid chromatography[15,16], capillary electrophoresis[17-21], pharmacokinetics[22,23], and fluorescence[24]. The reported spectrophotometric methods [4-6] do not discuss the stability of the methods and at the same time have low sensitivity [3-6]. More over, the methods are laborious and the effects of common excipients have not been investigated [3-6]. Sungur and Yurdakul[7] have determined acebutolol by UV Spectrophotometry. When compared to this method, our method is simple and does not involve any tedious/complex reaction conditions. This prompted us to develop simple, sensitive and accurate spectrophotometric methods for the determination of $\mathrm{ABH}$ in pure and pharmaceutical formulations. One of the well-established spectrophotometric methods is through ion-pair complex extraction. In this case, an ion-pair is formed between a basic compound and an anionic dye (e.g., bromophenol blue, bromocresol green, 
methyl orange, etc.). At a specific $\mathrm{pH}$, the ion-pair, which is immiscible with water is extracted into an organic solvent and the concentration of it is determined spectrophotometrically[25-28]. The ion-pair extraction technique has some difficulties and inaccuracies arising from incomplete extraction or the formation of emulsions between the organic solvent and the basic compound, containing solution. In response to the problems resulting from extraction of the ion-pair, few articles were published for the analysis of pharmaceutical compounds through ionpair formation without involving extraction [29-31]. In this paper, we describe the application of acidic dyes to the spectrophotometric determination of $\mathrm{ABH}$ without the application of buffers. The ionpair formed between the drug and sulphonphthalein dye, BCG/BTB requires no extraction and is measured directly in chloroform. The proposed methods are applied successfully for the determination of $\mathrm{ABH}$ either pure or in dosage forms with good accuracy and precision. Interference from some commonly co-formulated substances is also studied.

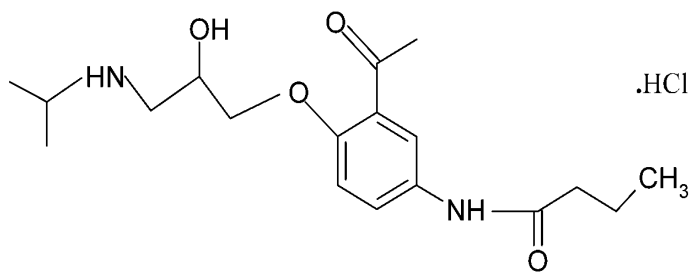

Figure 1. Structure of Acebutolol hydrochloride.

\section{Experimental}

\section{Apparatus}

The absorption spectra were recorded on a double beam CARY 50-BIO UV-Visible spectrophotometer (Varian, Australia) with $1 \mathrm{~cm}$ matched quartz cells.

\section{Materials and reagents}

Pure ABH sample was kindly provided by HIKAL Ltd., India. Commercial dosage forms were purchased from local sources.

Stock solutions of each of $0.1 \%$ of bromocresol green (BCG), and bromothymol blue (BTB) were prepared in chloroform. Standard solution of ABH was prepared by dis- solving $10 \mathrm{mg}$ in $100 \mathrm{~mL}$ of chloroform and further diluted as and when required.

\section{Procedures}

Recommended procedure and calibration curve

Suitable aliquot volumes of $\mathrm{ABH}$ solution were transferred into a series of $10 \mathrm{~mL}$ volumetric flasks, so that the final concentration is in the range stated in Table 1. Recommended volume of the dye solution was added (Table 1), mixed well and diluted to volume with chloroform. The absorbances of the resulting colored species were measured at the specified wavelength (Table 1) against chloroform.

Table 1. Optical characteristics and Statistical Data of the Regression Equations for the Reaction of $\mathrm{ABH}$ with $\mathrm{BCG}$ and $\mathrm{BTB}$.

\begin{tabular}{lll}
\hline Parameters & BCG & BTB \\
\hline Volume of the dye added $(\mathrm{mL})$ & 5 & 2 \\
$\lambda_{\max }(\mathrm{nm})$ & 412 & 415 \\
Beer's law limit $\left(\mu \mathrm{g} \mathrm{mL}^{-1}\right)$ & $0.5-13.8$ & $1.8-15.9$ \\
Molar absorptivity $\left(1 \mathrm{moL}^{-1} \mathrm{~cm}^{-1}\right)$ & $1.86 \times 10^{4}$ & $1.72 \times 10^{4}$ \\
Sandell's sensitivety $\left(\mathrm{ng} \mathrm{cm}^{-2}\right)$ & 19.667 & 21.692 \\
${\text { Regression equation }(\mathrm{Y})^{\mathrm{a}}}$ & & \\
Intercept, b & 0.0034 & 0.0023 \\
Slope, c & 0.049 & 0.0445 \\
Relative standard deviation $(\%)$ & 0.7777 & 1.2771 \\
Correlation coefficient $(\mathrm{r})$ & 0.9928 & 0.9978 \\
\hline
\end{tabular}

${ }^{\mathrm{a}} \mathrm{Y}=\mathrm{bX}+\mathrm{c}$, where $\mathrm{X}$ is the concentration of drug in $\left(\mu \mathrm{g} \mathrm{mL}^{-1}\right)$

${ }^{\mathrm{d}}$ Average of six determinations.

\section{Procedure for commercial dosage forms}

Weighed amounts of powdered tablets equivalent to $20 \mathrm{mg}$ of $\mathrm{ABH}$ were transferred into a $100 \mathrm{~mL}$ volumetric flask. The contents were shaken well with about $50 \mathrm{~mL}$ of chloroform for $30 \mathrm{~min}$. The flask was diluted up to the mark with the same solvent. It was filtered and preceded as described above. The nominal content of the tablets was determined from the calibration curve. 


\section{Results and Discussion}

\section{Absorption spectra}

The structure of $\mathrm{ABH}$ features its basic nature. This structure suggests the possibility of utilizing an anionic dye as chromogenic reagent. In chloroform, $\mathrm{ABH}$ is not an absorbing species in the visible region. The dyes employed have almost negligible absorbance (Fig 2). In contrast, when a solution of BCG or BTB in chloroform is added to the drug solution, an intense yellow colored product is produced immediately (Fig 2). This is due to the conversion of the dye into an open quinonoidal anionic derivative [32], which forms an ion-pair with $\mathrm{ABH}$.

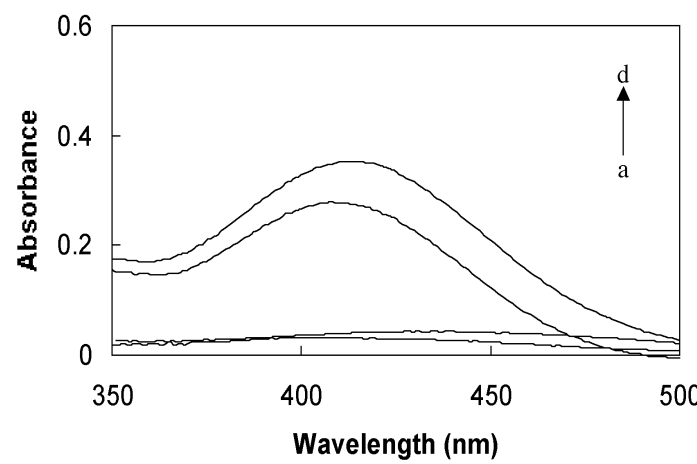

Figure 2. Absorption spectrum of reagent blanksBCG (a) and BTB (b), and ion-pair complexes of ABH $\left(8 \mu \mathrm{g} \mathrm{mL}^{-1}\right)$ with BCG (c) and BTB (d).

\section{Reaction conditions}

The experimental conditions were studied and it was found that $5 \mathrm{~mL}$ of BCG or $2 \mathrm{~mL}$ of BTB were sufficient to produce maximum and reproducible color. The color products were found to be stable for at least $1.5 \mathrm{~h}$.

\section{Investigation of the ABH-BCG ion-pair complex}

The composition of the ion-pair complex formed between $\mathrm{ABH}$ and $\mathrm{BCG} / \mathrm{BTB}$ was investigated by Job's method of continuous variation. It was found that the composition of drug to dye was $1: 1$ in both cases.

\section{Analytical performance}

\section{Linearity of the method}

Under the experimental conditions, linear correlations were obtained between the absorbances and $\mathrm{ABH}$ concentration over the ranges stated in Table 1 with good correlation coefficients and zero intercepts. The apparent molar absorptivities, Sandell's sensitivities and detection limits[33] were summarized in Table 1.

\section{Interference studies}

The effects of common excipients and additives were tested for their possible interferences in the assay of $\mathrm{ABH}$. It was also observed that the excipients such as talc, lactose, starch and magnesium stearate did not interfere with the assay, since the formation of an ion-pair complex with anionic dyes needs a basic moiety. The results have been tabulated in Table 2 for a representative dye, BTB.

Table 2. Determination of $\mathrm{ABH}$ a in Presence of Excipients by BTB Method.

\begin{tabular}{lcc}
\hline \multicolumn{1}{c}{ Material } & Amount $(\mathrm{mg}) \begin{array}{c}\% \text { Recovery of } \\
\mathrm{ABH} \pm \mathrm{RSD}^{\mathrm{b}}\end{array}$ \\
\hline Magnesium stearate & 30 & $97.8 \pm 0.72$ \\
Glucose & 40 & $98.6 \pm 0.89$ \\
Lactose & 40 & $98.7 \pm 0.93$ \\
Dextrose & 40 & $98.8 \pm 1.07$ \\
Starch & 30 & $100.2 \pm 0.88$ \\
Gum acacia & 40 & $99.2 \pm 1.10$ \\
Talc & 40 & $99.5 \pm 0.94$ \\
Sodium alginate & 25 & $98.4 \pm 0.14$ \\
\hline
\end{tabular}

${ }^{a} 5 \mu \mathrm{g} \mathrm{mL} \mathrm{mL}^{-1}$ of $\mathrm{ABH}$ taken.

${ }^{\mathrm{b}}$ Average of five determinations.

\section{Precision and accuracy}

In order to determine the accuracy and the precision of the method, standard solutions containing three different concentrations of $\mathrm{ABH}$ were analyzed in five replicates. The mean results obtained are summarized in Table 3. The small values of the standard deviation (SD), the relative standard deviation (RSD \%) and the mean standard analytical error (SAE) can be considered adequate for the quality control analysis of pharmaceutical preparations. 
Table 3. Evaluation of the Accuracy and Precision of the Proposed Method for ABH Determination.

\begin{tabular}{|c|c|c|c|c|c|}
\hline \multicolumn{3}{|c|}{ Dye $\mathrm{ABH}\left(\mu \mathrm{g} \mathrm{mL}{ }^{-1}\right)$} & \multirow[t]{2}{*}{ SD } & \multirow[t]{2}{*}{$\mathrm{RSD} \%$} & \multirow[t]{2}{*}{ SAE } \\
\hline & Added & Found $^{\text {a }}$ & & & \\
\hline \multirow[t]{4}{*}{$\mathrm{BCG}$} & & 2.01 & $4.650 \times 10^{-3}$ & 1.7743 & $2.079 \times 10^{-3}$ \\
\hline & 4 & 4.06 & $9.009 \times 10^{-3}$ & 1.5548 & $4.029 \times 10^{-3}$ \\
\hline & 6 & 5.97 & $6.722 \times 10^{-3}$ & 1.2772 & $3.006 \times 10^{-3}$ \\
\hline & 8 & 8.05 & $2.863 \times 10^{-3}$ & 0.7777 & $1.280 \times 10^{-3}$ \\
\hline \multirow[t]{3}{*}{ BTB } & 4 & 4.12 & $9.167 \times 10^{-3}$ & 1.2625 & $4.099 \times 10^{-3}$ \\
\hline & 6 & 6.04 & $3.807 \times 10^{-3}$ & 1.3599 & $1.702 \times 10^{-3}$ \\
\hline & 8 & 7.95 & $4.690 \times 10^{-3}$ & 1.2770 & $2.090 \times 10^{-3}$ \\
\hline
\end{tabular}

${ }^{a}$ Mean of five determinations

SD - standard deviation

RSD\% - relative standard deviation

SAE - standard analytical error.

\section{Pharmaceutical applications}

The proposed methods are equally accurate and precise as the Official method as indicated by the \% recovery. Table 4 shows the results obtained for the determination of $\mathrm{ABH}$ in commercial tablets by means of both the proposed methods and the Official method[2].

Table 4. Application of the Proposed Spectrophotometric Methods for the Determination of $\mathrm{ABH}$ in Dosage Forms.

\begin{tabular}{llll}
\hline $\begin{array}{l}\text { Commercial } \\
\text { product }\end{array}$ & \multicolumn{2}{c}{$\%$ Recovery ${ }^{\mathrm{a}} \pm$ SD } \\
BCG & \multicolumn{1}{c}{ BTB } & $\begin{array}{c}\text { Official method } \\
\text { (BP 2003) }\end{array}$ \\
\hline $\begin{array}{l}\text { ABH-400 } \\
\mathrm{mg} / \text { tablet }\end{array}$ & $99.78 \pm 0.81$ & $99.68 \pm 0.73$ & $99.5 \pm 1.3$ \\
$\mathrm{~F}$ & 1.15 & 1.92 & \\
$\mathrm{ABH}-200$ & 9.57 & 3.17 & \\
$\mathrm{mg} /$ tablet & $99.82 \pm 0.78$ & $99.85 \pm 0.84$ & $99.3 \pm 0.9$ \\
$\mathrm{~F}$ & 0.89 & 1.65 & \\
Sectral 200 & $99.92 \pm 1.1$ & $99.88 \pm 0.96$ & $99.5 \pm 1.2$ \\
$\mathrm{mg} /$ tablet & 1.24 & 1.43 & \\
$\mathrm{~F}$ & 1.19 & 1.56 & \\
\hline
\end{tabular}

The theoretical values of $\mathrm{t}$ and $\mathrm{F}$ at $\mathrm{P}=0.05$ are 2.31 and 6.39 , respectively.

${ }^{a}$ Mean of five determinations.

\section{Conclusions}

The proposed methods are rapid, simple, accurate and in addition, offer advantages in determining $\mathrm{ABH}$, (in pharmaceutical preparations), when extraction difficulties arise with other spectrophotometric methods. Hence, the proposed methods could be adopted routinely for quality control in pharmaceutical industries.

Received 18 December 2007

Accepted 08 May 2008

\section{References}

[1] Martindale, The Complete Drug Refernce, 33rd edition, Pharmaceutical Press, London, 2002, p. 825 and 612.

[2] British Pharmacopeial convention, Stationary office, London, 2003, p. 36.

[3] A.F. ElWalily, J Pharm Biomed Anal., 16 (1997) 21.

[4] A. Gölcü, C. Yücesoy, S. Serin, IL Farm., 59 (2004) 487.

[5] C.S.P. Sastry, R.T. Thirupathi, A. Sailaja, Talanta., 38 (1991) 1057.

[6] E.A. Hisham, M.M El-Henawee, H.M. El-Sayed, M.M. Ayad, Spectrochimica Acta Part A., 65 (2006) 1087.

[7] S. Sungur, G. Yurdakul, Scientia Pharmaceutica, 60 (1992) 125.

[8] R. Ficarra, P. Ficarra, M.R. Di-Bella, D. Raneri, S. Tommasini, M.L. Calabro, M.C. Gamberin, C. Rustichelli, J Pharm Biomed Anal., 23 (2000) 33.

[9] G.M. Hanna, F.E. Evans, J Pharm Biomed Anal., 24 (2000) 189. [10] B. Alpertunga, S. Sungur, L. Ersoy, S.Y. Manav, Arch Pharm., 323 (1990) 587.

[11] G.W. Caldwell, J.A. Masucci, M. Evangelisto, R. White, J Chromatogr A., 800 (1998) 161.

[12] A.J. Braza, P. Modamio, C.F. Lastra, E.L. Marino, Biomed Chrom., 16 (2002) 517.

[13] I. Lewandowska, J. Tyfczynska, M. Bujak Acta Pol Pharm., 46 (1989) 350.

[14] A.P. Argekar, S.G. Powar, J Pharm Biomed Anal., 21 (2000) 1137.

[15] V. Andrisano, R. Gotti, A. Leoni, V. Cavrini, J Pharm Biomed Anal., 21 (1999) 851.

[16] M.E. Abdel-Hamid, Il Farmaco., 55 (2000) 136.

[17] M.I. Maguregui, R.M. Jimenez, R.M. Alonso, J Chromatogr Sci., 36 (1998) 516.

[18] K.A. Assi, B.J. Clark, K.D. Altria, Electrophoresis., 20 (1999) 2723.

[19] A. Jouyban, M. Khoubnasabjafari, H.K. Chan, K.D. Altria, B.J. Clark, Chromatographia., 57 (2003) 191.

[20] A.C. Servais, M. Fillet, P. Chiap, A.M. Abushoffa, P. Hubert, J. Crommen J Sep Sci., 25 (2002) 1087.

[21] W. Lu, R.B. Cole, J Chrom B., 714 (1998) 69.

[22] M. Drozdzik, L. Domanski, J. Wojcicki, A. Pudlo, P. Machoy, J Cli Pharmacol., 43 (2003) 524.

[23] B. Telatynska, J. Wojcicki, M. Drozdzik, B. Gawronska-Szklarz, V. Sulzyc-Bielicka, R. Sterna, Pol J Pharmacol., 55 (2003) 81.

[24] J.F. Fernandez-Sanchez, A.S. Carretero, C. Cruces-Blanco, A. Fernandez-Gutierrez, J Pharm Biomed Anal., 31 (2003) 859.

[25] J. Milano, G.C. Simone, J Pharm Biomed Anal., 37 (2005) 639.

[26] N. Rahman, A. K. Nadeem, H.A.S. Najmul, Il Farmaco., 59 (2004) 47.

[27] A. Safwan, R. Al-Khalil, Il Farmaco., 60 (2005) 771.

[28] B.G. Gowda, M.B. Melwanki, J. Seetharamappa, J Pharm Biomed Anal., 25 (2001) 1021.

[29] M.M. El-Kerdawy, M.A. Moustafa, S.M. El-Ashry, D.R. ElWaseef, Anal Lett., 26 (1993) 1669.

[30] H.H. Abdine, J Pharm Sci., 14 (2000) 75.

[31] H. Abdine, F. Belal, N. Zoman, Il Farmaco . 57 (2002) 267. [32] T. Higuchi, H.E. Brochmann, Pharmaceutical Analysis., Interscience Publication, New York, pp. 413-418.

[33] J.C. Miller, J.N. Miller, Chapter 4, Wiley, New York, 1984, pp. 83-115. 